Artigos

Ana Clara Telles Cavalcante de Souza

Pontifícia Universidade Católica do Rio de Janeiro, Rio de Janeiro, RJ, Brasil

\title{
Sob o véu da intervenção: discursos de gênero na guerra do Afeganistão
}

Resumo: Na esteira dos atentados de 11 de setembro de 2001, a sociedade estadunidense viu emergir uma série de discursos de gênero que construiu a Guerra do Afeganistão como uma intervenção militar de "libertação" das mulheres afegãs. Avançando uma leitura crítica sobre a agenda internacional de Mulheres, Paz e Segurança, argumentamos que justificativas de gênero à Guerra no Afeganistão foram tornadas possíveis pela forma como a comunidade internacional lida politicamente com a interseção entre gênero e segurança em intervenções militares e missões de paz, invisibilizando o modo como ideais hegemônicos de masculinidade(s) subjazem à própria lógica norteadora das intervenções militares. Dessa forma, o processo de generização da 'guerra ao terror' foi tornado possível pelo avanço de entendimentos específicos sobre as mulheres e gênero dentro de uma agenda internacional de gender mainstreaming - e que tem como consequência última a despolitização do debate sobre gênero em segurança internacional. Palavras-chave: gênero; masculinidades; guerra ao terror; guerra do Afeganistão

\section{Introdução}

Em novembro de 2001, a então primeira-dama dos Estados Unidos, Laura Bush, dirigiu-se nacionalmente à população estadunidense para falar sobre a Guerra do Afeganistão. Nos dias que se seguiram aos atentados de 11/09, a Sra. Bush não falava sobre vingança, sobre campanhas de ódio contra os Estados Unidos ou, mesmo, sobre o direito da nação à autodefesa e à integridade de seu território. Em vez disso, chamava a população estadunidense a encontrar sua humanidade comum e a exercer sua empatia e solidariedade em relação às mulheres e crianças afegãs. Uma semana antes do feriado de Ação de Graças, Laura Bush foi colocada a falar no rádio no que ficou entendido como um esforço bem-sucedido de relações públicas para legitimar a intervenção militar dos Estados Unidos no Afeganistão. E, no que tange aos discursos de gênero que permearam a

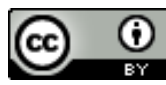

Esta obra está sob licença Creative Commons. 
preparação e a deflagração da guerra, sua fala é certamente lembrada como uma importante peça de propaganda da chamada 'guerra ao terror'.

Nesse quadro, o objetivo do presente artigo é duplo: em primeiro lugar, investigar como os Estados Unidos mobilizaram discursos de gênero para justificar em termos humanitários a intervenção militar no Afeganistão; e, também, compreender de que maneira isso se relaciona ao desenvolvimento de uma agenda internacional sobre mulheres, paz e segurança, especialmente no âmbito das Nações Unidas. Com o objetivo de abordar essas questões, é necessário analisar a forma como masculinidades e gênero são tratadas no debate sobre intervenções humanitárias e operações de paz, incluindo os esforços da comunidade internacional e, especificamente, do Conselho de Segurança da ONU (CSONU) de introduzir questões de gênero em sua agenda. Sendo assim, utilizando-nos de referenciais teóricos dos estudos de gênero dentro das Relações Internacionais - e, em específico, dos movimentos recentes relacionados à sua interseção com narrativas pós-estruturais e póscoloniais -, propomos uma leitura crítica tanto à forma como uma justificativa oportunista em termos de gênero tomou conta dos debates sobre a guerra ao terror no imediato pós-11/ 09, quanto à maneira com que se deram a centralização e a transversalização do gênero na agenda internacional - movimento conhecido, na ONU, como gender mainstreaming.

Nesse sentido, argumentamos que justificativas de gênero à Guerra no Afeganistão tornaram-se possíveis através de dois fatores diferentes, mas inter-relacionados: primeiramente, pela forma como a comunidade internacional tem lidado politicamente com a interseção entre gênero e segurança, especificamente quando ela se relaciona a intervenções militares e missões de paz; e, em segundo lugar, pela forma como intervenções militares têm sido informadas por representações de gênero e por ideais hegemônicos de masculinidade e feminilidade. Será argumentado que o processo de generização' da guerra ao terror foi tornado possível pelo avanço de entendimentos particulares e específicos sobre as mulheres e sobre igualdade de gênero dentro de uma agenda internacional restrita sobre gênero, paz e segurança que, ao mesmo tempo, invisibilizava a forma como normas e imaginações sobre gênero subjaziam à própria lógica norteadora das intervenções militares em âmbito internacional.

Cabe pontuar que, por gênero, entendemos um sistema de significados simbólicos que cria hierarquias sociais baseadas em associações e contraposições hierárquicas entre supostas características 'masculinas' e 'femininas' (WADLEY, 2010, p. 39). Por trás do uso desse conceito há a intenção de tornar visíveis as relações de poder que constituem as normas e as imaginações sobre gênero, bem como a forma como ele se sustenta através da oposição entre signos dicotômicos que representam ideais de masculinidade(s) e feminilidade(s). Localizar essa interpretação de gênero no centro da nossa análise nos permite o distanciamento e a problematização da forma como o gênero vem ocupando a agenda internacional de paz e segurança, especialmente no âmbito das Nações Unidas, onde é entendido em termos marcadamente liberais como equidade de gênero e participação política de mulheres. Em última instância, tal interpretação limitada constitui uma das condições de possibilidade para a emergência de discursos de justificação da violência política que reproduzem hierarquias de gênero em vez de desafiá-las - argumento que será abordado mais profundamente no decorrer do texto.

Aqui, cabe deixar claro que avançar um olhar crítico sobre como a comunidade internacional tem lidado politicamente com a interseção entre gênero e segurança não significa, nem deve significar, o esvaziamento da agenda políica sobre violência de gênero contra meninas e mulheres em situações de conflito armado. Ao contrário, o esforço

' Neologismo que tem como objetivo evitar o uso do estrangeirismo "genderization". 
de reflexão crítica aqui apresentado busca contribuir, precisamente, para se pensar mais profundamente sobre as dimensões subjetivas que sedimentam as relações de poder em termos de gênero - e, que, em última instância, reverberam os 'problemas concretos' em termos de segurança que milhares de mulheres ao redor do mundo são obrigadas a enfrentar cotidianamente. De fato, o artigo parte de uma concepção ontológica que evita, inclusive, resvalar para a dicotomia que contrapõe 'reflexão teórica' e 'mundo real', baseando-se no entendimento oposto de que teorizar é uma prática cotidiana que ajuda a construir a política internacional como ela se apresenta - ou seja, que uma reflexão crítica também tem o potencial de transformar práticas políticas (Marysia ZALEWSKI, 1996).

Na primeira seção do artigo, comentaremos brevemente sobre os principais avanços na agenda de paz e segurança no que tange à introdução de questões de gênero, sobretudo na pauta do CSONU. Argumentar-se-á que o instrumento do CSONU mais sensível a gênero a Resolução 1325, de outubro de 2000 - deriva tanto de desenvolvimentos da agenda de proteção de civis quanto nos esforços anteriores da ONU de gender mainstreaming, i.e., de incorporação da igualdade de gênero em sua agenda prioritária. Na seção seguinte, o processo de generização da Guerra do Afeganistão - de legitimação via uso de representações de gênero e de alegadas motivações em direção à equidade entre gêneros - será detalhado com maior foco em sua natureza discursiva. Na terceira seção, serão finalmente analisadas as justificativas à 'guerra ao terror', tendo como pano de fundo o desenvolvimento da agenda sobre gênero, paz e segurança pelo CSONU. Por fim, e por via de conclusão, algumas considerações serão feitas sobre o potencial despolitizador do gender mainstreaming, em conversa com perspectivas críticas de Relações Internacionais.

\section{Mulheres, Gênero, Paz e Segurança na agenda internacional}

Em outubro de 2000, o CSONU adotou por unanimidade sua primeira resolução sobre Mulheres, Paz e Segurança. ${ }^{2}$ Estabelecendo parâmetros claros para a integração de perspectivas de gênero à agenda internacional de segurança, a Resolução 1325 - a partir de agora, referida como RES/1325 - reconheceu "o importante papel das mulheres na prevenção e resolução de conflitos" e "a necessidade de intensificar seu papel de decisão em relação à prevenção e à resolução de conflitos". ${ }^{3}$ Igualmente, a RES/1325 expressou preocupação com os efeitos adversos dos conflitos armados em mulheres e crianças e destacou a importância de abordar a violência baseada em gênero como um tema de paz e segurança internacionais.

Ao trazer questões de gênero para a agenda formal do CSONU pela primeira vez, a RES/1325 se baseava em dois movimentos normativos já estabelecidos no âmbito das Nações Unidas: por um lado, a preocupação crescente sobre a proteção de civis em conflitos armados, assim como sobre a participação de crianças como soldados armados durante conflitos intraestatais - refletida em resoluções anteriores do órgão, como a RES/ 1261 (1999), a RES/1265 (1999), a RES/1296 (2000) e a RES/1314 (2000); por outro, o reconhecimento da importância de fortalecer os direitos da mulher como parte de esforços internacionais de combate à desigualdade de gênero em todo o mundo. Uma vez intersecionados pela RES/1325, esses dois movimentos abriram caminho para um novo entendimento das relações entre mulheres e a agenda de paz e segurança, que pretendia

\footnotetext{
${ }^{2}$ Em letras maiúsculas por ter se tornado o nome de uma agenda específica da ONU e de suas agências, especialmente em termos transversais a outras agendas, programas e projetos.

${ }^{3}$ Todas as citações diretas que aparecem no texto foram traduzidas a partir de uma adaptação livre, i.e., feita pela própria autora do artigo, com o objetivo de facilitar a leitura (CSONU, 2000, p. 1; Tarja VÄYRYNEN, 2004).
} 
ver as primeiras como vítimas de conflitos armados, mas também como agentes em sua prevenção e resolução.

No que tange ao comprometimento anterior da ONU no fortalecimento de uma agenda internacional sobre igualdade de gênero, a IV Conferência Mundial sobre Mulheres, organizada em Pequim, em 1995, parece ser um marco histórico. Além de ter mobilizado aproximadamente 50 mil participantes de todo o mundo - dos quais um terço era mulher -, a Conferência de Pequim culminou em uma Plataforma para a Ação com estratégias recomendadas para lidar com questões de gênero em doze "áreas críticas de preocupação". Sobre a relação específica entre mulheres e conflitos armados, a Plataforma de Ação de Pequim propunha como objetivos estratégicos [1] o aumento da participação de mulheres na resolução de conflitos em todos os seus níveis de decisão; [2] o avanço de formas não violentas de resolução de conflitos; [3] a promoção da contribuição das mulheres para o fortalecimento de uma cultura de paz; entre outras questões. Reconhecendo o papel crucial das mulheres durante conflitos armados na preservação da ordem social e também como educadoras para a paz em suas comunidades, a Plataforma de Ação também reafirmava a necessidade de uma "política ativa e visível de mainstreaming de uma perspectiva de gênero em políticas e programas" (ONU, 1995, p. 57).

De acordo com Nicole DETRAZ (2012), a ONU adotou duas principais estratégias para atingir seus objetivos de igualdade de gênero: gender balance - algo como 'equilíbrio de gênero', ou a equiparação numérica de homens e mulheres em seus postos de trabalho - e gender mainstreaming. Nos termos da própria organização, gender mainstreaming veio a ser definido como

o processo de análise das implicações para mulheres e homens de toda ação planejada incluindo legislação, políticas e programas em todas as áreas e em todos os níveis [...] [cujo] fim último é alcançar a igualdade de gênero (ONU, 2002, p. V).

O Plano de Ação da Namíbia (2000), por exemplo, pedia "[o mainstreaming de] uma perspectiva de gênero em operações multidimensionais de apoio à paz" (ONU, 2000, p. 2), em que homens e mulheres teriam acesso igual a todas as instâncias de poder em um processo de paz. Junto a outros instrumentos (formais e informais) de gender mainstreaming na agenda de paz e segurança da ONU se encontra a RES/1325, bem como subsequentes resoluções do CSONU em matéria similar.

No Preâmbulo da Resolução, torna-se evidente que o CSONU parte de um entendimento sobre igualdade de gênero como uma condição para "a manutenção da paz e segurança [internacionais]" (CSONU, 2000, p. 1). Uma vez que a desigualdade de gênero, a opressão e a violência sexistas são entendidas como ameaças ao estabelecimento de uma comunidade internacional pacífica - um princípio declarado da Carta das Nações Unidas -, o avanço de uma agenda de gênero sobre segurança internacional se torna crucial para o alcance de uma paz duradoura e sustentável. Nesse sentido, o objetivo de incorporar uma perspectiva de gênero em operações de paz e na negociação e implementação de acordos de paz envolve: [a] ser sensível à violência sexual e de gênero contra mulheres e crianças; [b] oferecer treinamento sensível a gênero ao pessoal militar e civil envolvido em operações de paz; [c] atentar-se às necessidades especiais das mulheres em contextos de conflito armados; [d] apoiar iniciativas locais de mulheres de fortalecimento da paz; e [e] avançar medidas de proteção e respeito aos direitos humanos de mulheres, incluindo participação igualitária no sistema político.

Sendo assim, na RES/1325, a igualdade de gênero torna-se mainstreamed não tanto como um benefício per se, mas como forma de alcançar a manutenção da paz e da segurança internacionais. Tal entendimento será novamente reproduzido em resoluções posteriores do 
CSONU sobre gênero, paz e segurança, como a RES/1820 (2008) e a RES/1888 (2009), que lidam especificamente com violência sexual em contextos de conflito armado. Em ambos os documentos, a violência sexual e de gênero é uma vez mais entendida como uma ameaça à responsabilidade das Nações Unidas de prevenção à insegurança internacional, uma vez que pode "exacerbar significativamente situações de conflito armado e [...] impedir a restauração da paz e da segurança internacionais" (CSONU, 2008, p. 2). Nesse contexto, a demanda por participação mais igualitária das mulheres em operações e negociações de paz, incluindo um percentual maior de mulheres como membros de forças armadas e policiais, é vista como forma eficiente de alcance de maior representatividade social, aumentando a probabilidade de obtenção de acordos de paz mais sustentáveis; e também como necessária para o estabelecimento de medidas mais eficazes de combate a crimes de gênero em situações de guerra (partindo de um entendimento de que mulheres são mais sensíveis e confiáveis aos olhos da população local).

Notavelmente, a política de tolerância zero em relação à exploração e ao abuso sexual - que se aplica, em teoria, à totalidade do pessoal de operações de paz sobre responsabilidade da ONU - tem sido frequentemente corroborada em resoluções do CSONU sobre violência sexual e de gênero. Em 2005, o CSONU emitiu declaração presidencial na qual reconhecia a responsabilidade do Secretário-Geral da ONU, bem como dos Estadosmembros da organização, em prevenir a exploração e o abuso sexual por parte de seus agentes de operações de paz. No entanto, no que tange às resoluções específicas do CSONU sobre operações de paz em curso, parece haver inconsistência em como a política de tolerância zero tem sido abordada, indicando que o Conselho tem delegado suas responsabilidades aos países contribuintes (SCR, 2003).

Ainda assim, alguns acadêmicos afirmam que questões de gênero estão alcançando posições cada vez mais altas na agenda de paz e segurança da ONU, particularmente no que diz respeito à violência sexual em conflitos armados (Torunn TRYGGESTAD, 2014). Desde 1998, o estupro foi tornado crime de guerra e crime contra a humanidade pelo Estatuto de Roma do Tribunal Penal Internacional (TPI), seguindo avanços anteriores feitos por tribunais ad hoc na lugoslávia e em Ruanda (Mark ELLIS, 2006). ${ }^{4}$ Conquistas recentes nessa área incluem também a indicação de um Representante Especial do Secretário-Geral sobre Violência Sexual em Conflitos Armados (2010), o estabelecimento definitivo da ONU Mulheres (2011) e a adoção - por parte de organizações regionais - de resoluções, diretivas e diretrizes baseadas na RES/1325 (TRYGGESTAD, 2014). Ainda assim, Sandra WHITWORTH (2004) salienta que a estrutura da ONU torna difícil incluir gênero como prioridade na agenda da organização devido a seu "protocolo diplomático, disputas de território entre departamentos, e a proteção da reputação de (determinados) Estados-membros" (p. 204).

Apesar de alegações sobre avanços e sobre inconsistências, permanece importante analisar a RES/1325 a partir de uma lente crítica feminista, olhando especificamente para que tipo de entendimento sobre mulher e gênero ela avança. Um ano após a RES/1325 ser adotada pelo CSONU, a Guerra do Afeganistão era parcialmente justificada em termos humanitários como necessária para a libertação de mulheres e crianças afegãs do regime Talibã. Na próxima seção, olharemos para os principais discursos da Guerra do Afeganistão sobre gênero, focando especificamente em como líderes políticos estadunidenses e a mídia tentaram legitimar a intervenção através da mobilização de representações discursivas de gênero. Depois disso, analisaremos criticamente a relação entre discursos de gênero sobre a Guerra do Afeganistão e a forma como a comunidade internacional tem incorporado questões de gênero a seus objetivos de paz e segurança, argumentando que $\circ$ uso

${ }^{4}$ Para uma visão crítica sobre violência sexual e Direito Penal Internacional, ver Rosalind DIXON (2002). 
oportunista de justificativas de gênero para o engajamento em intervenções militares tornase possível pela consolidação de entendimentos específicos sobre mulheres e sobre gênero na agenda de segurança internacional.

\section{"Mulheres e crianças": discursos de gênero e a Guerra do Afeganistão}

A America está começando a entender que os sonhos dos terroristas e do Talibã são o pesadelo acordado das mulheres e crianças afegãs. George W. BUSH, 2001.

Sob o nome oficial de 'Operação Paz Duradoura', a Guerra do Afeganistão foi iniciada na esteira dos ataques de 11/09 como uma resposta militar unilateral dos Estados Unidos e de seus aliados ao terrorismo. As primeiras operações dos Estados Unidos ocorreram em outubro de 2001, na forma de ofensivas aéreas contra o Talibã e também de suporte militar às forças afegãs em atuação. Nos primeiros anos, as Forças Armadas estadunidenses evitaram a formação de uma força multinacional que trabalhasse na fase de estabilização pós-invasão, em parte por entender que isso poderia afetar negativamente seus esforços para eliminar a Al Qaeda e o Talibã (Astri SUHRKE, 2009). Em dezembro do mesmo ano, o CSONU adotou a RES/1378, que chamava os Estados-membros a apoiarem o estabelecimento de uma administração transitória através de assistência militar, econômica e humanitária.

De acordo com Fatima AYUB e Sari KOUVO (2008), apesar de a Guerra do Afeganistão não ser explicitamente uma intervenção humanitária, mas, sim, uma operação militar, ${ }^{5}$ os líderes políticos estadunidenses efetivamente vieram abraçar uma retórica humanitária em torno de sua ofensiva militar em território afegão. Evitando obter prescrições para a ação através do Capítulo VII - "a partir de um desejo de preservar maior flexibilidade em como [...] a resposta seria conduzida" (Simon CHESTERMAN, 2003, p. 164) -, a Guerra do Afeganistão pode ser mais bem compreendida como um caso de uso unilateral da força em autodefesa, como foi reconhecido pelo CSONU meses depois (AYUB e KOUVO, 2008). Ainda assim, associada à retórica de autodefesa desencadeada pelo luto nacional pós-11/09, a administração Bush tentaria legitimar a intervenção militar no Afeganistão em termos de direitos humanos - como o único meio de proteger os direitos fundamentais da população afegã contra o regime opressivo do Talibã -, especialmente para uma audiência liberal (James KURTH, 2006).

Laura SHEPHERD (2006) chama a atenção para o fato de que justificativas discursivas à Guerra do Afeganistão em termos humanitários vieram junto a construções particulares de gênero, especialmente durante a preparação para a deflagração da 'Operação Paz Duradoura'. Como Krista HUNT (2006) aponta, "[d]esde 11 de Setembro de 2001, um conjunto de histórias de guerra sobre a liberação das mulheres emanou da Casa Branca" (p. 51). Simultaneamente ao engajamento dos Estados Unidos e de seus aliados na intervenção militar no Afeganistão, a sociedade estadunidense testemunhava a ascensão de certo tipo de discurso humanitário que colocava as "mulheres e crianças" afegãs como vítimas que precisavam ser salvas através da força militar. Como meio de formar consenso público em torno da guerra ao terror, discursos de gênero sobre a Guerra do Afeganistão moldaram o apoio público ao que ficou definido como o 'projeto de libertação' para 'civilizar' o Afeganistão (Jasmin ZINE, 2006; HUNT, 2006).

${ }^{5}$ Uma leitura compreensiva sobre os diferentes conceitos de intervenção humanitária pode ser encontrada em Kai KENKEL (2012). 
Nas palavras de Laura Bush (2001), ao falar pelo rádio à população estadunidense,

todos nós temos a obrigação de falar. Nós podemos ter vindo de diferentes contextos e fés - mas pais de todo o mundo amam seus filhos. Nós respeitamos nossas mães, nossas irmãs e nossas filhas. Lutar contra a brutalidade contra mulheres e crianças não é uma expressão de uma cultura em particular; é a aceitação de nossa humanidade comum - um compromisso compartilhado por pessoas de boa vontade em todos os continentes. Por conta dos nossos recentes ganhos militares em muitas partes do Afeganistão, as mulheres não estão mais prisioneiras em suas casas. Elas podem ouvir música e ensinar suas filhas sem medo de punição. No entanto, os terroristas que ajudaram a governar aquele país agora conspiram e planejam em muitos países. E eles precisam ser detidos. A luta contra o terrorismo é também a luta pelos direitos e pela dignidade das mulheres.

De acordo com Shepherd (2006), representações de gênero em torno da Guerra do Afeganistão serviram para "criar e perpetuar um entendimento particular da situação e organizar uma resposta baseada nesse entendimento" (p. 19-20). Especificamente, a autora enfatiza como o período imediatamente posterior ao 11/09 viu a (re)emergência de discursos dominantes sobre os Estados Unidos que dependiam de um processo anterior de masculinização da identidade estadunidense, bem como de imagens femininas complementares, doméstica e internacionalmente. Nesse sentido, Shepherd (2006) identifica quatro meios principais através dos quais uma identidade estadunidense generizada foi reimaginada: através do Cidadão Decente Comum - que é forte o suficiente para superar a tragédia, mas também se sacrifica em nome de sua nação; a Figura de Autoridade - a 'parte cerebral' do Cidadão Comum, ou o homem em posição de tomada de decisão sobre o futuro da nação; a Compradora Feliz - uma categoria femininizada de indivíduos passivos à espera de proteção no espaço privado do lar; e, finalmente, as Vítimas Sem Esperanças - as mulheres estrangeiras que precisam ser salvas.

Nas palavras de Shepherd (2006),

a passividade femininizada das 'mulheres' na nação se sobrepõe à construção da 'mulher' fora dela, identificadas como Vítimas Desamparadas, o que tem importantes ramificações para a generização do 'inimigo externo'. O discurso de gênero é altamente racializado, uma vez que 'a posição discursiva privilegiada' ocupada pela 'nação' é reforçada por "toda uma história de dominância global - de imperialismo e colonialismo" (TOMLINSON, 1991, p. 28). As mulheres de fora são reconhecíveis dentro desse discurso como variações do que Mohanty $(1991$, p. 56$)$ chama de "mulher média do terceiro mundo" que "leva uma vida essencialmente truncada baseada no seu gênero feminino (leia-se: sexualmente limitada) e por ser do 'terceiro mundo' (leia-se: ignoranta, pobre, não-educada, ligada às tradições, doméstica, orientada para a família, vitimizada etc.)" (p. 25).

De maneira similar, Krista Hunt e Kim RYGIEL (2006) argumentam que entendimentos generizados sobre a guerra ao terror dependiam não apenas da "mulher vitimizada que precisa ser resgatada" (p. 9), mas também de seus "salvadores hipermasculinizados" e de seus "covardes opressores" (p. 9). Dessa forma, a construção da Guerra do Afeganistão como uma guerra a ser lutada em nome das mulheres dependia essencialmente de uma construção masculinizada da nação estadunidense - e de seus cidadãos, soldados, políticos - como salvadores. Da mesma maneira, as "mulheres e crianças" afegãs precisavam ser resgatadas das mãos de antagonistas masculinos - sejam eles os combatentes do Talibã ou os homens muçulmanos em geral. Nesse sentido, Hunt (2006) argumenta que, além de ganhar apoio público, a construção discursiva de gênero sobre a Guerra do Afeganistão era um modo efetivo de identificar o inimigo como bárbaro, como um animal, como menos humano. 
Nesse contexto, conexões entre entendimentos feministas sobre a Guerra do Afeganistão e perspectivas anti ou pós-coloniais se tornam mais evidentes. Para Jasmin Zine (2006), por exemplo, a guerra ao terror operava sob lógicas contraditórias no que concernia ao 'outro' racializado: por um lado, uma atitude repressiva em direção ao homem árabe muçulmano; por outro, o desejo de libertar as mulheres muçulmanas de seus opressores. Na esteira dos ataques de $11 / 09$, ela acrescenta, as mulheres muçulmanas estão presas em uma posição desconfortável entre a racialização e a generização da guerra ao terror, com consequências últimas para a forma como seus corpos serão narrados, definidos e regulados (ZINE, 2006). Zine (2006) argumenta que, no cerne dessa construção discursiva, uma narrativa orientalista sobre o corpo das mulheres muçulmanas insiste em vê-las como uma espécie de 'construção maleável' para servir a propósitos políticos, culturais e ideológicos.

Em meio a esse processo, discursos e narrativas sobre as mulheres afegãs se baseavam significativamente em representações midiáticas. Como Carol STABILE e Deepa KUMAR (2005) mostram, no ano que se seguiu ao $11 / 09$, o número de artigos sobre as mulheres do Afeganistão na mídia impressa estadunidense aumentou em seis vezes quando comparado aos 18 meses anteriores aos ataques, ao passo que o número de programas televisivos cresceu até 20 vezes durante o mesmo período. Da mesma forma, Zine (2006) salienta o papel dos conglomerados de mídia nos Estados Unidos, especialmente aqueles considerados, no período, como apoiadores da administração Bush, na reprodução de uma imagem arquetípica das mulheres muçulmanas. Nesse sentido, o processo de generização da Guerra do Afeganistão foi estabelecido através de discursos políticos e midiáticos, de forma que ambos são quase indistinguíveis. Até mesmo o discurso de Laura Bush, em novembro de 2001, foi um esforço maior de relações públicas do governo, pensado em coordenação com a divulgação, um dia depois, de relatório do Departamento de Estado sobre a "Guerra do Talibã contra as Mulheres" (STABILE e KUMAR, 2005).

Finalmente, a construção da Guerra do Afeganistão em termos de gênero é um processo em constante reprodução, com reverberações até os dias de hoje. Em 2004, três anos após a deflagração da guerra ao terror, a administração Bush ainda enfatizava a libertação das mulheres afegãs como uma das principais conquistas da intervenção militar dos Estados Unidos no país (HUNT, 2006). Em 2010, quase dez anos depois do início da guerra, o periódico semanal Time trazia em sua capa a face mutilada de Aesha Mohammadzai, jovem afegã que teve seu nariz e suas orelhas cortadas fora por seu marido (um combatente do Talibã) e sua família, sob os dizeres "O Que Acontece se Deixarmos o Afeganistão". A capa da Time parece endossar o argumento de Jasmin Zine (2006) de que, no fim das contas, o corpo das mulheres muçulmanas é o local último de disputadas no contexto da guerra do terror - corpos a serem salvos, resgatados, preservados.

\section{Desvelando a intervenção: um olhar crítico à agenda sobre mulheres, paz e segurança}

A RES/ 1325 tinha como objetivo promover perspectivas de gênero sobre missões de paz de duas maneiras diferentes: ao abordar a necessidade de mecanismos de proteção para mulheres e crianças em situações de conflito armado; e ao afirmar a importância da participação igualitária das mulheres em todas as esferas de operações de paz. Ainda assim, apesar dos supostos esforços de dar agência às mulheres na agenda de paz e segurança, a RES/1325, assim como resoluções subsequentes sobre o mesmo tema, parece se basear mais significativamente em um entendimento vitimizador, em vez de empoderador, das mulheres. Não à toa, Charli CARPENTER (2006) destaca que, dentre todas as resoluções do CSONU emitidas entre 1999 e 2003 sobre proteção de civis, a expressão "mulheres e 
crianças" foi usada 163 vezes, enquanto "mulheres como combatentes" foi mencionada em apenas seis ocasiões.

Apesar de ser verdade que muitas mulheres estão, de fato, vulneráveis à violência durante conflitos armados, priorizar uma imagem das mulheres como vítimas de insegurança é um modo de homogeneizar as experiências das mulheres em termos de guerra (DETRAZ, 2012). Representar mulheres como vítimas também vem junto a um entendimento sobre mulheres como inerentemente pacíficas ou portadoras de qualidades naturais para a resolução de conflitos. De acordo com Nicole Detraz (2012), uma consequência desse entendimento é a invisibilidade das mulheres que atuam como combatentes em conflitos armados, o que pode levar à sua exclusão do processo de negociação da paz como partes envolvidas. Uma agenda para a integração das mulheres em processos de paz que não aborda a variedade de papéis que as mulheres podem exercer em contextos de conflito armado reforça certos estereótipos de gênero na relação entre mulheres, paz e segurança enquanto ignora outras nuances, reproduzindo relações desiguais entre gêneros.

Ainda, uma questão deve ser enfatizada em relação à associação que a RES/1325 (entre outras resoluções) faz entre mulheres e crianças. O uso extensivo do termo "mulheres e crianças" indica a subestimação das formas como as mulheres podem ter agência em política internacional, especialmente no que tange à segurança. Colocar "mulheres" e "crianças" lado a lado tende a infantilizar as primeiras e reafirmar a posição passiva delegada ao 'feminino' na agenda de paz e segurança (CARPENTER, 2006). Nesse sentido, ao CSONU - assim como à ONU, ao Secretretário-Geral e demais atores - é atribuída a posição de protetor masculino, que convida as mulheres, como agentes passivos de violência, a participar da paz.

Essa relação se torna clara no seguinte trecho da RES/1820, em que as mulheres parecem ser um 'corpo estranho' que precisa ser incluído (em vez de atores do processo):

O Conselho de Segurança [...] [c]lama ao Secretário-Geral e seus Enviados Especiais que convide[m] as mulheres a participar de discussões pertinentes à prevenção e à resolução de conflitos, à manutenção da paz e da segurança, e à construção da paz pós-conflito, e encoraja todas as partes de tais negociações a facilitar a participação igual e total das mulheres em níveis de tomada de decisão (CSONU, 2008, p. 4).

De modo parecido, discursos de gênero sobre a Guerra do Afeganistão partem da mesma imagem em que "mulheres e crianças" são colocadas de lado como indivíduos sem agência. Das vinte vezes em que Laura Bush menciona a palavra "mulher" durante sua fala ao rádio em 2001 , um terço delas foi na forma da expressão "mulheres e crianças". Nesse caso particular, ver as mulheres afegãs como indivíduos passivos e vítimas de seu próprio contexto político torna difícil ouvir suas opiniões e perspectivas sobre si mesmas (HUNT, 2006). Dessa forma, a construção da guerra ao terror em termos de gênero depende significativamente da imagem das mulheres como sujeitos sem voz (como fotos, histórias, mas não agentes), para que outros atores aleguem falar por elas.

Na literatura sobre gênero, guerra e Relações Internacionais, importantes vozes emergiram para questionar a forma como a prática convencional em política internacional (incluída, aqui, a prática acadêmica) tende a reproduzir a dicotomia de gênero entre 'protetores' e 'protegidos'. Por um lado, tal dicotomia reproduz relações hierárquicas entre gêneros na medida em que, ao protetor masculino, será sempre esperado o ato de salvação aos sujeitos femininos em necessidade de proteção. Como a teórica feminista de política internacional Cynthia ENLOE (2000) sublinha, a homens e mulheres serão esperadas reações opostas, mas complementares, face a uma situação de perigo que se conforme com os papéis sociais de gênero que devem exercer. Por outro lado, a dicotomia protetor/protegido 
torna invisível a forma como esses atores que supomos precisar de proteção podem, de fato, tornarem-se mais inseguros e vulneráveis à violência quando tal dicotomia está em operação. Nesse sentido, perspectivas de gênero sobre paz e segurança devem desafiar os papéis (de gênero) tradicionais daqueles que consideram a si mesmos 'protetores' ou 'salvadores', incluindo a noção de que o Estado é a manifestação última dessa proteção.

Da mesma forma, Hunt e Rygiel (2006) sublinham que a 'história oficial' da guerra ao terror que dá conta de sua contribuição para a libertação das mulheres desvia a atenção da violência que as mulheres sofrem como consequência da intervenção militar no Afeganistão. Os discursos de gênero que envolvem a questão são seriamente desafiados por relatos independentes sobre a incapacidade da Guerra do Afeganistão em prover algum tipo de 'libertação' às mulheres afegãs (HUNT, 2006). Como Hunt (2006) demonstra, quando escutamos o que as mulheres afegãs têm a dizer sobre sua própria situação, algumas delas alegam que a Guerra do Afeganistão, ao contrário das expectativas, exacerbou sua situação de vulnerabilidade e incentivou a resistência a qualquer tipo de sensibilidade política a questões de gênero que passam a ser vistas como imposições do Ocidente às culturas locais. Como aponta Zine (2006),

por mais deploráveis que sejam as condições enfrentadas pelas mulheres afegãs sob o regime talibã anteriormente apoiado pelos EUA, o fato de que sua luta foi estrategicamente posicionada como 'merecedora do horário nobre' apenas durante as violentas campanhas da guerra ao terror reforça o papel de disfarce político ativado para generizar a empatia pela campanha militar como um ato de 'liberação' das mulheres muçulmanas dos homens muçulmanos fanáticos [...]. Através desse processo, as lutas das mulheres afegãs são reduzidas à guerra contra o fundamentalismo, apagando outros importantes fatores que afetam suas vidas, como a pobreza, os deslocamentos internos e a falta de serviços de saúde e da habilidade de abordar até mesmo as necessidades mais básicas, o que as campanhas militares estavam exacerbando (ldem, p. 34-35).

Essa questão se relaciona à discussão apresentada por Sophia DINGLI (2015) sobre o lugar do silêncio nas Relações Internacionais. Aprofundando o debate já bem colocado pelas literaturas críticas sobre o silenciamento na política internacional como processo político de violência, ${ }^{6}$ Dingli aponta que, mais do que fruto de desempoderamento material ou discursivo, o ato político de silenciar e marginalizar vozes também advém do que chama de "distribuição do sensível", ou uma economia de significados que disciplina a sensibilidade e exclui formas de falar de modo que o silêncio deixa de ser (apenas) o ato de não dizer para ser, sobretudo, fruto do ato de não ser capaz de escutar. A principal consequência desse processo, segundo Dingli (2015), é que o silêncio "não apenas exclui experiências, mas, principalmente, nega existências, tornando-as inadmissíveis para consideração", sobretudo quando pertencente ao que é considerado não ocidental. ${ }^{7}$ No caso da justificação discursiva para a Guerra do Afeganistão, o debate foi construído de tal forma, que as falas das mulheres afegãs sobre suas próprias experiências se tornam ininteligíveis, uma vez que não se encaixam nos termos de discussão que as tornariam capazes de sensibilizar os atores políticos envolvidos.

É igualmente importante atestar o óbvio acerca do envolvimento ativo da primeiradama na construção de discursos de gênero sobre a Guerra do Afeganistão. A fala de Laura Bush à população estadunidense sobre a necessidade de dar proteção às mulheres afegãs deriva de tradição bem estabelecida na Casa Branca de 'dar voz' às primeiras-

\footnotetext{
${ }^{6}$ Por exemplo, Enloe (2000)

${ }^{7}$ Idem (p. 6).
} 
damas para que falem ao público sobre 'questões de mulheres', tais como ajuda humanitária e políticas públicas familiares. Além de ser esse ato, por si só, reafirmador da dicotomia de gênero entre público e privado - já bem explorada pela literatura feminista -, ao ceder espaço a ela, a Casa Branca parecia querer construir uma imagem da opressão do Talibã contra as mulheres afegãs como uma questão de interesse privado das famílias estadunidenses - contribuindo, desse modo, para a despolitização da questão, como será comentado adiante.

Torna-se, ao mesmo tempo, claro que, apesar da alegação de Laura Bush de que lutar a guerra em nome dos direitos das mulheres afegãs é "aceitar nossa humanidade comum", hierarquias emergem na medida em que alguns sujeitos são mais humanos que outros. Ao retratar essas mulheres como atores sem agência, sem voz e sem papel ativo em seus próprios destinos, os líderes políticos dos Estados Unidos pareciam vê-las "como um [eu] inferior, alguém que aspira (ou deveria aspirar) ao alcance do mesmo nível de civilização ou governança que [eles] têm" (Costas DOUZINAS, 2007, p. 22). Construir a Guerra do Afeganistão em termos humanitários desse tipo parece também contribuir para a construção de fronteiras entre o 'eu' e o 'outro' de tal maneira, que não há espaço para o diálogo. Como Vivienne JABRI (2007) argumenta, intervenções baseadas em clamores humanitários têm um caráter desumanizador em relação às populações envolvidas, que se tornam híbridos entre 'humanos' (que precisam ser salvos) 'não humanos' (cujas vidas são descartáveis em nome da guerra).

O debate se engrandece quando se consideram as leituras feministas críticas sobre o próprio fenômeno da guerra e da produção de (in)segurança. O acadêmico Jonathan D. Wadley (2010) é um dos estudiosos de gênero a explorar como performances de (in)segurança - relacionadas à construção de ameaças e de respostas políticas a elas se tornam inteligíveis através de ideais binários sobre 'masculinidade(s)' e 'feminilidade(s)', que, por sua vez, ajudam a construir o imaginário político sobre as relações internacionais baseado em oposições hierárquicas entre o 'doméstico' e o 'internacional', a 'ordem (interna)' e o 'caos (externo)'. Nesse contexto, o autor dá destaque à 'performance da proteção', já comentada anteriormente, cujos efeitos políticos podem ser vistos no ato intrinsecamente generizado do fazer guerra em âmbito internacional. Outras pensadoras feministas, como Sandra Whitworth (1994), J. Ann TICKNER (2001), Nicole Detraz (2012) e Cynthia Enloe (1993; 2000), debruçaram-se sobre a forma como o fenômeno do militarismo e os processos de militarização são informados por imaginários de gênero que determinam mais amplamente padrões de conduta na política internacional relacionados à guerra e à violência política, com importantes consequências para a segurança das mulheres 'dentro' e 'fora' do contexto de conflitos armados. Com base em reflexões críticas sobre a relação entre guerra e hierarquias de gênero, surgem perspectivas feministas de natureza pacifista a partir de distintas vertentes teóricas, como as liberais, as construtivistas, as socialistas e as anarquistas (Elizabeth FRAZER e Kimberly HUTCHINGS, 2013).

Por outro lado, e em explícita oposição ao movimento pacifista feminista, autoras como Laura SJOBERG (2006) propõem uma reflexão sobre a própria possibilidade de se reinterpretar criticamente o fenômeno da guerra, e, mais especificamente, o conceito da 'guerra justa', ${ }^{8}$ através de uma ética feminista baseada no conceito de "cooperação empática". Por "cooperação empática" a autora entende "uma política colaborativa de diálogo e identificação emocional" (SJOBERG, 2006, p. 49) capaz de informar uma

${ }^{8}$ Conceito amplamente debatido nas Relações Internacionais e que se relaciona à construção de parâmetros de avaliação que determinem se uma guerra é justa ou injusta. Uma leitura convencional sobre o tema pode ser encontrada em Michael WALZER (1977). 
perspectiva feminista sobre 'guerra justa' baseada na inclusão da diversidade, na valorização das diferenças e na priorização do diálogo - um conceito de 'empatia' sensivelmente diferente daquele proposto por Laura Bush e instrumentalizado como justificativa para a intervenção. Em outras palavras, enquanto algumas autoras feministas questionam as fundações éticas do fazer guerra ao entendê-lo como um ato essencialmente generizado, Sjoberg, entre outras autoras, ${ }^{9}$ considera a possibilidade de se pensar eticamente a guerra para além de sua generização, a partir de um olhar crítico feminista sobre suas possibilidades e sobre suas limitações como ferramenta política.

Dito isso, há alguma relação entre a forma como a comunidade internacional tem integrado uma perspectiva de gênero à sua agenda de paz e segurança e o processo de legitimação da Guerra do Afeganistão em termos de gênero? Em primeiro lugar, é possível argumentar que a ONU não tem trazido uma perspectiva compreensiva de gênero aos debates contemporâneos sobre intervenções militares e operações de paz internacionais. Como Tarja Väyrynen (2004) argumenta, o discurso de gênero da organização sobre missões de paz é "uma abordagem gerencialista e de resolução de problemas às operações de paz" (p. 126) derivada de uma atitude moderna liberal contra a ambivalência e a incerteza. Em um contexto de guerra e conflito, diz Väyrynen, essa lógica moderna reduz a violência política a problemas técnicos e recomenda soluções despolitizadas a problemas intrinsecamente políticos. Da mesma forma, o CSONU procura por soluções técnicas para assegurar seu objetivo de "manter a paz e a segurança internacionais". Nesse cenário, uma abordagem sensível a gênero não é entendida como um benefício per se, mas uma tentativa de lidar efetivamente com as ambivalências e incertezas das situações de conflitos armados. Não existe esforço para refletir criticamente sobre como relações de gênero se associam a estruturas binárias que naturalizam dicotomias como aquelas entre o 'humano' e o ‘não humano', 'nós' e 'outros', 'protetor' e 'protegido', 'guerra' e 'paz'; nem em abordar outras formas de hierarquias de gênero que não passam pela opressão de um 'masculino bárbaro' sobre suas 'vítimas indefesas', mas que se relacionam a um campo mais complexo de relações de poder (VÄYRYNEN, 2004). Nas palavras de Väyrynen (2004),

o discurso da ONU sobre operações de paz representa uma racionalidade cognitivainstrumental no sentido de que a preservação do sistema de Estados constitui seu principal objetivo. O sistema de Estados tem de se adaptar às condições de guerra e conflito que são vistas como a incorporação da contingência e da anomalia do sistema. Um meio para a adaptação são as operações de paz, que objetivam a dominação instrumental da violência. A dominação cognitiva-instrumental é reforçada pelo entendimento metafórico da guerra nos discursos de operações de paz da ONU, nomeadamente a guerra como epidemia ou doença e as operações de paz como remédio para a enfermidade (ldem, p. 130).

Sendo assim, o gênero é mainstreamed apenas na medida em que não desafia as relações de poder que subjazem à política internacional contemporâena, significativamente baseada na reprodução dessas dicotomias. Uma vez que a comunidade internacional não questiona a lógica de gênero por trás das intervenções humanitárias, ela pavimenta o caminho para a reprodução de hierarquias dicotômicas entre 'masculinidade(s)' e 'feminilidade(s)' para além da agenda feminista liberal. O processo de construção de protetores e protegidos em termos de masculino e feminino não é desafiado pela construção atual de questões de gênero na agenda de paz e segurança, de forma que os alegados 'avanços' de instrumentos como a RES/1325 se restringem a tentativas técnicas de solucionar

${ }^{9}$ Um bom mapeamento desse debate no Reino Unido é feito por Frazer e Hutchings (2013). 
problemas que não podem ser abordados tecnicamente, mas através da construção de uma consciência política generizada.

Nesse sentido, discursos de gênero sobre a Guerra do Afeganistão se tornam possíveis, em parte, pela forma restrita com que questões de gênero vêm sendo introduzidas na agenda de segurança internacional. Ao construir as mulheres como vítimas, ao infantilizálas, ao negá-las agência ou voz, o debate sobre mulheres, paz e segurança deixa espaço para perspectivas oportunistas e hierárquicas sobre questões de gênero. Associados a uma perspectiva orientalista do 'não Ocidente', os discursos de gênero sobre a guerra ao terror consolidam um entendimento masculinista de intervenções humanitárias que não é desafiado de nenhuma maneira pelos desenvolvimentos correntes na agenda de paz e segurança. Ao contrário, os termos do debate frequentemente reforçam tais representações de gênero e, em última instância, aprofundam a dicotomia masculino/feminino.

\section{Conclusão: gender mainstreaming como despolitização?}

Nesse artigo, pretendíamos analisar criticamente as tentativas discursivas de legitimação da Guerra do Afeganistão em termos humanitários e de gênero. Argumentouse que o processo de generização da guerra ao terror foi tornado possível no contexto do desenvolvimento de uma agenda internacional mais ampla sobre gênero, paz e segurança que avançava entendimentos particulares e restritos sobre mulheres e sobre igualdade de gênero. Igualmente, ao não desafiar as representações de gênero reproduzidas pelas intervenções militares e pelas operações de paz, essa agenda deixou espaço para o uso de justifcativas de gênero para legitimar a Guerra do Afeganistão, um processo que se baseou significativamente em representações masculinas e femininas sobre quem salva e quem é protegido.

No entanto, a título de conclusão, deve-se salientar que deixar de lado reflexões mais críticas de gênero sobre o debate a respeito das intervenções militares e operações de paz pode contribuir para aprofundar o processo de despolitização de tais operações, especificamente quando elas são estabelecidas em termos humanitários. Para Jabri (2007), a construção de tais intervenções humanitárias como matéria de direito internacional, por exemplo, tem levado ao aprofundamento de dicotomias entre atores 'dentro' e 'fora da lei', em que tecnicalidades legais têm maior voz que a política. De modo similar, não abordar como dicotomias de gênero constituem o debate atual sobre intervenções humantárias contribui para tornar hierarquias invisíveis e priorizar políticas de gênero de resolução de problemas em detrimento de reflexões críticas sobre como relações de poder operam através de entendimentos hierárquicos sobre masculinidade(s) e feminilidade(s) dentro da política internacional.

Nesse sentido, o processo de generização da Guerra do Afeganistão parece ser mais um fator de contribuição para construir a desigualdade de gênero como uma questão despolitizada. Ao retratá-la como uma questão de 'humanidade', tais discursos tornam invisíveis os mecanismos através dos quais as relações de gênero na sociedade afegã operam, avançando um entendimento sobre os atores envolvidos como não humanos - sejam eles os homens brutais ou as mulheres passivas. É precisamente a despolitização de questões de gênero no Afeganistão que permitiu à administração Bush promover, por um lado, a retórica do respeito ao direito das mulheres afegãs e avançar, por outro, uma agenda conservadora em relação à mesma questão em nível doméstico (HUNT e RYGIEL, 2006).

Sendo assim, o processo de gender mainstreaming, quando usado de forma a cooptar demandas feministas a uma agenda de solução de problemas, pode ter um potencial despolitizador, escondendo tensões políticas invisibilizadas sob uma superfície de guias, 
planos de ação e outras tecnicalidades. Quando o objetivo é "não pensar de modo inovador ou criticar as estruturas que tornaram o gênero silenciado em primeiro lugar, [... . mas adicionar o elemento do gênero às práticas estadocêntricas e patriarcais existentes de resolução de conflitos e construção da paz" (VÄYRYNEN, 2004, p. 138), pode-se dar início a um ciclo de soluções arbitrárias que não necessariamente resolve problemas políticos. Como esclarecido anteriormente, isso não significa dizer que abordar a violência de gênero contra meninas e mulheres em situações de conflito armado não deve ser tópico relevante na agenda de paz e segurança internacionais. Ao contrário, trata-se precisamente da recusa a ser insensível e indiferente às relações de poder mais complexas que, em âmbito internacional, informam os problemas 'da vida real' no que tange às mulheres e à paz.

\section{Referências}

AYUB, Fatima; KOUVO, Sari. "Righting the course? Humanitarian intervention, the war on terror and the future of Afghanistan". International Affairs, v. 84, n. 4, p. 641-657, 2008.

BUSH, George W. President Signs Afghan Women and Children Relief Act. US Department of State Archive, 2001. Disponível em: http://2001-2009.state.gov/p/sca/rls/rm/6816.htm. Acesso em: 20/06/2015.

BUSH, Laura. Radio Address by Mrs. Bush. The American Presidency Project, 2001. Disponível em: http://www.presidency.ucsb.edu/ws/?pid=24992. Acesso em: 20/06/2015.

CARPENTER, Charli. Innocent Women and Children, Gender, Norms and the Protection of Civilians. Burlington: Ashgate, 2006.

CHESTERMAN, Simon. "Humanitarian Intervention and Afghanistan". In: WELSH, J. (Ed.). Humanitarian Interventions and International Relations. Oxford: Oxford University Press, 2003.

CSONU. Resolution 1325, 2000. Disponível em: http://daccess-dds-ny.un.org/doc/UNDOC/ GEN/NOO/720/18/PDF/N0072018.pdf. Acesso em: 20/06/2015.

. Resolution 1820, 2008. Disponível em: http://www.securitycouncilreport.org/ atf/cf/ \%7B65BFCF9B-6D27-4E9C-8CD3CF6E4FF96FF9\%7D/CAC\%20S\%20RES\%201820 .pdf. Acesso em: 20/06/x2015.

DETRAZ, Nicole. International Security and Gender. Cambridge: Polity Press, 2012.

DINGLI, Sophia. "We need to talk about silence: re-examining silence in international relations theory". European Journal of International Relations, v. 21, n. 4, p. 721-742, 2015.

DIXON, R. "Rape as a crime in international humanitarian law: where to from here?". European Journal of International Law, v. 13, n. 2, p. 697-719, 2002.

DOUZINAS, Costas. "The Many Faces of Humanitarianism". Parrhesia, n. 2, p. 1-28, 2007.

ELLIS, Mark. "Breaking the Silence: Rape as an International Crime". Case Western Reserve Journal of International Law, n. 38, p. 225-247, 2006.

ENLOE, Cynthia. The Morning After: sexual politics at the end of the Cold War. Berkeley/ Londres: University of California Press, 1993.

Bananas, Beaches and Bases: making feminist sense of international politics. Berkeley: University of California Press, 2000.

FRAZER, Elizabeth; HUTCHINGS, Kimberly. "Revisiting Ruddick: feminism, pacifism and nonviolence". Journal of International Political Theory, v. 10, n. 1, p. 109-124, 2013.

HUNT, Krista. "'Embedded Feminism' and the War on Terror”. In: HUNT, Krista; RYGIEL, Kim (Eds.). (En)Gendering the War on Terror: war stories and camouflaged politics. Burlington: Ashgate, 2006.

; RYGIEL, Kim. “(En)Gendered War Stories and Camouflaged Politics”. In: HUNT, Krista; RYGIEL, Kim (Eds.). (En)Gendering the War on Terror: war stories and camouflaged politics. Burlington: Ashgate, 2006. 
JABRI, Vivienne. War and the transformations of global politics. London: Palgrave Macmillan, 2007.

KENKEL, Kai M. "O dilema interno da soberania: a evolução das normas de intervenção". In: KENKEL, Kai M.; MORAES, Rodrigo F. (Orgs.). O Brasil e as operações de paz em um mundo globalizado. Brasília: Instituto de Pesquisa Econômica Aplicada, 2012.

KURTH, James. "Humanitarian Intervention After Iraq: Legal Ideals vs. Military Realities". Orbis Winter, v. 50, n. 1, p. 87-101, 2006.

ONU. Beijing Platform for Action, 1995. Dispnoível em: http://www.un.org/womenwatch/ daw/ beijing/pdf/BDPfA\%20E.pdf. Acesso em: 20/06/2015.

Windhoek Declaration and Namibia Plan of Action, 2000. Disponível em: http:// www.un.org/womenwatch/osagi/wps/windhoek_declaration.pdf. Acesso em: 20/06/2015.

Gender Mainstreaming: an overview. Office of the Special Adviser on Gender Issues and Advancement of Women, 2002. Disponível em: http://www.un.org/womenwatch/ osagi/pdf/e65237.pdf. Acesso em: 20/06/2015.

SCR. Women, Peace and Security: sexual violence in conflict and sanctions, 2003. Disponível em: http://www.securitycouncilreport.org/cross-cutting-report/women-peace-and-securitysexual-violence-in-conflict-and-sanctions.php?print=true. Acesso em: 20/06/2015.

SHEPHERD, Laura. "Veiled References: constructions of gender in the Bush administration discourse on the attacks on Afghanistan post-9/1 1". International Feminist Journal of Politics, v. 8, n. 1, p. 19-41, 2006.

SJOBERG, Laura. Gender, justice and the wars in Iraq: a feminist reformulation of just war theory. Lanham: Lexington Books, 2006.

STABILE, Carol; KUMAR, Deepa. "Unveiling imperialism: media, gender and the war on Afghanistan". Media, Culture and Society, v. 27, n. 5, p. 765-682, 2005.

SUHRKE, Astri. "The dangers of a tight embrace: externally assisted statebuilding in Afghanistan". In: PARIS, Roland; SISK, Timothy D. (Orgs.). The Dilemmas of Statebuilding: Confronting the Contradictions of Postwar Peace Operations. Nova York: Routledge, 2009.

TICKNER, J. Ann. Gendering World Politics: issues and approaches in the post-Cold War Era. Nova York: Columbia University Press, 2001.

TRYGGESTAD, Torunn. "Gender Perspectives in Peace Research". Lecture at Peace Research Institute Oslo (PRIO), 24 de junho de 2014.

VÄYRYNEN, Tarja. "Gender and UN Peace Operations: the confines of modernity". International Peacekeeping, v. 11, n. 1, p. 125-142, 2004.

WADLEY, Jonathan. "Gendering the State: performativity and protection in international security". In: SJOBERG, Laura (Ed.). Gender and International Security: feminist perspectives. Londres: Routledge, 2010.

WALZER, Michael. Just and Injust Wars: a moral argument with historical illustrations. Nova York: Basic Books, 1977.

WHITWORTH, Sandra. Men, Militarism and UN Peacekeeping. Boulder, CO: Lynne Rienner Publishers, 2004.

ZALEWSKI, Marysia. "'All these theories yet the bodies keep piling up': theory, theorists, theorising". In: SMITH, S.; BOOTH, K.; ZALEWSKI, M. (Eds.). International Theory: Positivism and Beyond. Cambridge: Cambridge University Press, 1996.

ZINE, Jasmin. "Between Orientalism and Fundamentalism: muslim women and feminist engagement". In: HUNT, Krista; RYGIEL, Kim (Eds.). (En)Gendering the War on Terror: war stories and camouflaged politics. Burlington: Ashgate, 2006. 
[Recebido em 08/07/2015, reapresentado em $28 / 08 / 2016$ e aprovado em 10/01/2017]

Under the Vell of Intervention: Gender Discourses in the War in Afghanistan

Abstract: In the aftermath of the 9/11 attacks, the American society saw the emergence of a set of gender discourses that framed the War in Afghanistan as a military intervention to "free" the Afghan women. Drawing on a critical reading on the Women, Peace and Security agenda, we argue that gender justifications of the War in Afghanistan were made possible by the way the international community has been treating the issue of gender and security when it comes to military interventions and peacekeeping missions, invisibilizing how hegemonic ideals of masculinity(ies) inform the very logics of military interventions. In this sense, the process of gendering the "war on terror" was made possible by the advancement of particular and restricted understandings on women and gender equality within a broader international agenda on gender mainstreaming - which had as ultimate consequence the depolitization of the debate on gender and international security.

Keywords: Gender; Masculinities; War on terror; War in Afghanistan

Ana Clara Telles Cavalcante de Souza (anaclara.telles@hotmail.com) é doutoranda do Instituto de Relações Internacionais da Pontifícia Universidade Católica do Rio de Janeiro, onde é bolsista de Doutorado do Conselho de Desenvolvimento Científico e Tecnológico (CNPq).

1312 Estudos Feministas, Florianópolis, 25(3): 1297-1312, setembro-dezembro/2017 